\title{
Effect of Additive Size on the Densification and Thermal Conductivity of AlN Ceramics with $\mathrm{MgO}-\mathrm{CaO}-\mathrm{Al}_{2} \mathrm{O}_{3}-\mathrm{SiO}_{2}$ Additives
}

\author{
Hwa-Jun Lee***, Woo-Seok Cho*, Hyeong Jun Kim*, Hyung-Tae Kim*, and Sung-Soo Ryu**t \\ *Engineering Ceramic Center, Korea Institute of Ceramic Engineering and Technology, Icheon 17303, Korea \\ **School of Advanced Materials Science and Engineering, Sungkyunkwan University, Suwon 16419, Korea \\ (Received August 31, 2016; Revised October 26, November 8, 2016; Accepted November 8, 2016)
}

\begin{abstract}
In this study, we investigate the effect of additive size on the densification and thermal conductivity of AlN ceramics with $\mathrm{MgO}-\mathrm{CaO}-\mathrm{Al}_{2} \mathrm{O}_{3}-\mathrm{SiO}_{2}$ (MCAS) additives. Micro-sized MCAS powder prepared via melting and nano-sized MCAS powder synthesized via the polymeric complex method are used as sintering additives. We analyze the densification behavior of AlN added with 5 wt.\% of MCAS by dilatometry as well as by isothermal sintering in the temperature range of $1300 \sim 1700^{\circ} \mathrm{C}$. AlN exhibits higher sinterability with nano-MCAS than with micro-MCAS, and both specimens approach their maximum densities when sintered at $1600^{\circ} \mathrm{C}$ for $4 \mathrm{~h}$. The thermal conductivities of AlN with $5 \mathrm{wt} \%$ of nano- and micro-MCAS additives sintered at $1600^{\circ} \mathrm{C}$ are 82.6 and $32.0 \mathrm{~W} / \mathrm{mK}$, respectively. We find that nano-MCAS is more effective in sintering of AlN ceramics at lower temperatures, and thus for enhancing their thermal conductivities.
\end{abstract}

Key words : AlN, Sintering additive, Densification, Thermal property

\section{Introduction}

A luminum nitride (AlN) exhibits high thermal conductivity, low dielectric constant, high electrical resistivity, and a thermal expansion coefficient comparable to that of $\mathrm{Si}$. These unique properties make it a promising material for use as a packaging substrate for high-power integrated circuits. $^{1-5)} \mathrm{AlN}$ is a strong, covalently-bonded material, which makes sintering very difficult. Full densification requires temperatures over $1900^{\circ} \mathrm{C}$. In addition, the sintering atmosphere must be properly controlled to prevent oxidation at temperatures above $1000^{\circ} \mathrm{C}$.

These issues have attracted significant interest in the development of finer AlN powders and additives such as alkaline-earth and rare-earth oxides to enable sintering at lower temperatures. ${ }^{5-12)}$ Komeya et al..$^{9,10)}$ approached the issue systematically and reported that sintering additives such as $\mathrm{CaCO}_{3}, \mathrm{Y}_{2} \mathrm{O}_{3}$, etc. are very effective in the pressureless sintering of AlN at $1800^{\circ} \mathrm{C}$. These additives play two roles. First, they interact with the $\mathrm{Al}_{2} \mathrm{O}_{3}$ layer on the $\mathrm{AlN}$ surface to form liquid aluminates, enabling liquid-phase sintering. Second, they enhance the thermal conductivity by decreasing the dissolved oxygen content of the AlN lattice.

However, the aforementioned sintering temperature is very high. It increases manufacturing costs, and causes undesirable, exaggerated grain growth that adversely affects the mechanical properties of AlN. Furthermore,

${ }^{\dagger}$ Corresponding author : Sung-Soo Ryu

E-mail : ssryu@kicet.re.kr

Tel : +82-31-645-1447 Fax : +82-31-645-1485 there are restrictions on the selection of metal electrodes for co-firing of AlN multilayer substrates. Thus, the densification of AlN at low temperatures has recently attracted significant interest. ${ }^{13-18)}$

Troczynski and Nicholson densified AlN with $9 \mathrm{wt} \%$ of a $\mathrm{CaO}-\mathrm{Y}_{2} \mathrm{O}_{3}-\mathrm{SiO}_{2}-\mathrm{La}_{2} \mathrm{O}_{3}-\mathrm{CeO}_{2}$ system at $1600^{\circ} \mathrm{C} .{ }^{13)}$ Streicher et $a l{ }^{14)}$ also densified AlN to its maximum density with 0.5 wt $\%$ of $3 \mathrm{CaO}_{3}-\mathrm{SiO}_{2}-\mathrm{Al}_{2} \mathrm{O}_{3}$ or $\mathrm{CaCO}_{3}$ at $1650^{\circ} \mathrm{C}$. Jarrige et al. ${ }^{15)}$ sintered $\mathrm{AlN}$ at $1600^{\circ} \mathrm{C}$ with $2 \mathrm{wt} \%$ of $12 \mathrm{CaO}_{7}-\mathrm{Al}_{2} \mathrm{O}_{3}$ $\mathrm{Y}_{2} \mathrm{O}_{3}$ or $12 \mathrm{CaO}_{7}-\mathrm{Al}_{2} \mathrm{O}_{3}-\mathrm{CaYAlO}_{4}$, and achieved up to $97 \%$ of the theoretical density. Watari et al. ${ }^{16)}$ used the $\mathrm{Y}_{2} \mathrm{O}_{3}-\mathrm{CaO}$ $\mathrm{Li}_{2} \mathrm{O}$ system as a sintering additive and reported thermal conductivities of $100-172 \mathrm{~W} / \mathrm{mK}$ for bodies sintered at $1600^{\circ} \mathrm{C}$.

Liu et al. produced a densely-sintered AlN with $\mathrm{CaF}_{2}$ and $\mathrm{YF}_{3}$ at $1650^{\circ} \mathrm{C}$, and reported a thermal conductivity of $187 \mathrm{~W} / \mathrm{mK}^{17)}$ Qiao et al. also synthesized a densely-sintered AlN with $2 \mathrm{wt} \%$ of $\mathrm{CaF}_{2}$ and $\mathrm{Y}_{2} \mathrm{O}_{3}$ added at $1650^{\circ} \mathrm{C}$, and reported a thermal conductivity of $148 \mathrm{~W} / \mathrm{mK}$. ${ }^{18)}$

In addition to the cases above, there have been many recent studies of low-temperature sintering of AlN using additives made from glass ceramics with low melting temperatures. ${ }^{19-21)}$ For example, Yang et al. $^{21)}$ prepared $\mathrm{MgO}-$ $\mathrm{CaO}-\mathrm{Al}_{2} \mathrm{O}_{3}-\mathrm{SiO}_{2}$ (MCAS) glass via a sol-gel method, and verified that it is an effective additive for the low temperature sintering of AlN. A previous study ${ }^{22)}$ demonstrated that $5 \mathrm{wt} \%$ of micro-sized MCAS glass prepared via melting causes AlN to densify at $1600^{\circ} \mathrm{C}$. However, its thermal conductivity was $25 \mathrm{~W} / \mathrm{mK}$, which is much lower than with $\mathrm{Y}_{2} \mathrm{O}_{3}$ or $\mathrm{CaO}$ additives.

It is logical to reason that the particle size of the additive 
can play an important role on the sinterability and thermal conductivity of AlN. Some studies have reported that smaller particles provide better densification and thermal conductivities. $^{23,24)}$ Qiao et $a l .{ }^{24)}$ fully densified $\mathrm{AlN}$ at $1600^{\circ} \mathrm{C}$ by incorporating 3.53 and $2.0 \mathrm{wt} \%$ of nano-sized $\mathrm{Y}_{2} \mathrm{O}_{3}$ and $\mathrm{CaO}$ additives, respectively. They reported that a significant enhancement in thermal conductivity is possible in this system. Lee et $a l .{ }^{25)}$ recently confirmed that the polymeric complex method (PCM) can be used to synthesize nanoMCAS with particle sizes around $50 \mathrm{~nm}$, and that the resulting nano-additive is very effective in the sintering of AlN at low temperatures.

In this study, we used the MCAS system as an additive for low-temperature sintering of $\mathrm{AlN}$, and investigated the effect of its particle size on densification and thermal conductivity. We prepared two additives, a micro-sized MCAS powder via the melting method, and a nano-sized powder via the PCM.

\section{Experimental Procedure}

We used a commercial AlN powder (Grade H, Tokuyama, Japan) synthesized via carbothermal reduction and nitridation. Two additives, nano- and micro-sized MCAS were synthesized via melting and the PCM, respectively. We used a melting procedure described in a previous study. ${ }^{22)}$ First, the starting materials consisting of $5 \mathrm{wt} \%$ of $\mathrm{MgO}, 19 \mathrm{wt} \%$ of $\mathrm{CaO}, 26 \mathrm{wt} \%$ of $\mathrm{Al}_{2} \mathrm{O}_{3}$, and $50 \mathrm{wt} \%$ of $\mathrm{SiO}_{2}$ were mixed in a ball mill, and the mixture was melted at $1500^{\circ} \mathrm{C}$. Next, the melt was quenched and dry-ground in a planetary mill to produce a fine powder.

We also performed the PCM using a procedure described in a previous study. ${ }^{25)}$ The starting materials were citric acid $\left(\mathrm{C}_{6} \mathrm{H}_{8} \mathrm{O}_{7}\right)$, ethylene glycol $\left(\mathrm{HOCH}_{2} \mathrm{CH}_{2} \mathrm{OH}\right)$, magnesium nitrate hexahydrate $\left(\mathrm{Mg}\left(\mathrm{NO}_{3}\right)_{2} 6 \mathrm{H}_{2} \mathrm{O}\right)$, calcium carbonate $\left(\mathrm{CaCO}_{3}\right)$, aluminum nitrate nonahydrate $\left(\mathrm{Al}\left(\mathrm{NO}_{3}\right)_{3} 9 \mathrm{H}_{2} \mathrm{O}\right)$, and tetraethyl orthosilicate $\left(\mathrm{C}_{8} \mathrm{H}_{20} \mathrm{O}_{4} \mathrm{Si}\right)$. The concentrations were set to yield the same composition as produced via melting. First, a mixture of citric acid (CA) and ethylene glycol (EG) (CA : EG = 1:5 molar ratio) was prepared, and $\mathrm{Mg}\left(\mathrm{NO}_{3}\right)_{2}, \mathrm{CaCO}_{3}, \mathrm{Al}\left(\mathrm{NO}_{3}\right)_{3}$, and $\mathrm{C}_{8} \mathrm{H}_{20} \mathrm{O}_{4} \mathrm{Si}$ were sequentially dissolved into the solution at $90^{\circ} \mathrm{C}$. The mixture was thermally polymerized at $300^{\circ} \mathrm{C}$ and then at $400^{\circ} \mathrm{C}$ for $5 \mathrm{~h}$. This processing yielded a black solid. The solid was thermally treated again in air for $5 \mathrm{~h}$ at $700^{\circ} \mathrm{C}$, resulting in a nano-sized MCAS powder.

Figure 1 shows field emission scanning electron microscopy (FE-SEM) images of the two additives. The nano- and micro-sized MCAS comprise particles of about $50 \mathrm{~nm}$ and 5 $\mu \mathrm{m}$, respectively. Fig. 2 is the particle-size distribution of the micro-sized MCAS, as determined via laser diffraction. It confirms an average particle size of about $5 \mu \mathrm{m}$.

For sintering experiments, AlN powder was mixed with $5 \mathrm{wt} \%$ of either MCAS additive in a mini mill (pulverisette 23, FRITSCH, Germany). The mixture was pressed in a super-alloy mold (10 $\mathrm{mm}$ diameter) at $20 \mathrm{MPa}$, then exposed
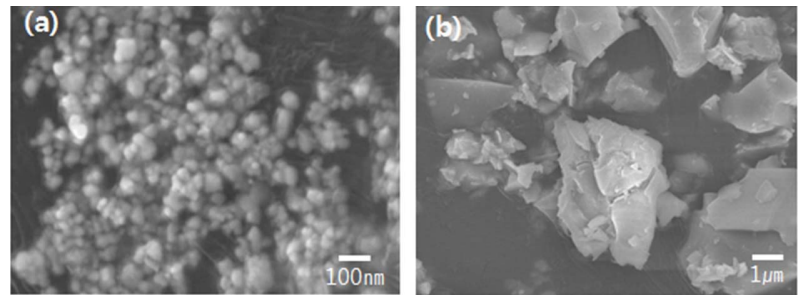

Fig. 1. SEM images of two types of $\mathrm{MgO}-\mathrm{CaO}-\mathrm{Al}_{2} \mathrm{O}_{3}-\mathrm{SiO}_{2}$ (MCAS) powders used as the sintering additive for AlN ceramics; (a) polymerized complex method and (b) melt method.

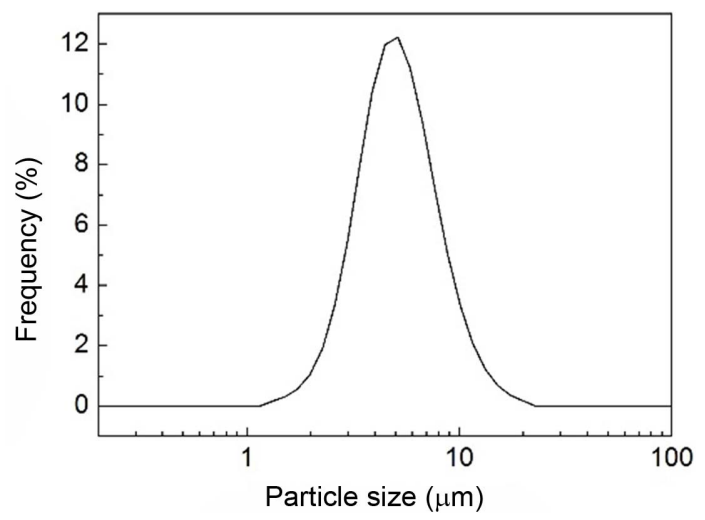

Fig. 2. Particle size distribution of the MCAS powder prepared by the melt method.

to cold isostatic pressing at $200 \mathrm{MPa}$, which produced discshaped green samples. Their sintering shrinkage was measured using a dilatometer (DIL-402C, Netzsch, Germany) by heating at a rate of $5^{\circ} \mathrm{C} / \mathrm{min}$ and holding at $1600^{\circ} \mathrm{C}$ for $4 \mathrm{~h}$.

Isothermal sintering was carried out in a sintering furnace (Thermvac, Korea) with a tungsten heating element. Samples were placed on a tungsten plate coated with BN powder, inside a tungsten crucible. The furnace pressure was reduced to $100 \mathrm{~m}$ Torr and nitrogen was introduced at a flow rate of $2 \mathrm{~L} / \mathrm{min}$. Then, the temperature was increased to a set point between 1300 and $1700^{\circ} \mathrm{C}$ at a rate of $5^{\circ} \mathrm{C} / \mathrm{min}$. Sintering proceeded at that temperature for $4 \mathrm{~h}$.

The sintered density was measured via Archimedes' principle, and its microstructure was analyzed via FE-SEM (JSM-9701, JEOL, Japan). The crystalline phase of the sintered body was identified via X-ray diffraction (XRD, D/ max-2500, RIGAKU, Japan) at $40 \mathrm{kV} / 200 \mathrm{~mA}$, in the $2 \theta$ range of $10-80^{\circ}$, with a scan rate of $5^{\circ} / \mathrm{min}$.

The sintered AlN disks were prepared via a typical procedure for thermal conductivity measurements, and tested using a laser flash analyzer (LFA447, NETZSCH, Germany) at $25^{\circ} \mathrm{C}$. We calculated the thermal conductivity ( $\lambda$, $\mathrm{mm}^{2} / \mathrm{s}$ ) using the following equation:

$$
\lambda(\mathrm{T})=\alpha(\mathrm{T}) \times \rho(\mathrm{T}) \times C_{\mathrm{p}}(\mathrm{T})
$$

Here, $\rho(\mathrm{T})$ : density $\left(\mathrm{g} / \mathrm{cm}^{3}\right)$

$C_{\mathrm{p}}$ : specific heat $(\mathrm{J} / \mathrm{g} \cdot \mathrm{K})$ 


\section{Results and Discussion}

\subsection{Shrinkage behavior}

Figure 3(a) shows the linear shrinkage behaviors of AlN sintered bodies containing $5 \mathrm{wt} \%$ of different sizes of MCAS. That of pure AlN is included in the figure for comparison. The addition of micro-MCAS to AlN causes sintering to begin at $1300^{\circ} \mathrm{C}$. We attribute this to liquid-phase sintering by the melted MCAS glass, which is presumed to begin formation at its melting point of $1253^{\circ} \mathrm{C}{ }^{22)}$

We observe similar behavior with nano-MCAS, although the shrinkage is more severe. Linear shrinkage levels for the AlN samples with nano-, micro-, and no-additive cases are $10.0,6.8$, and $2.0 \%$, respectively. The AlN sample synthesized with the nano-additive exhibits the highest shrinkage. Fig. 3(b) shows the shrinkage rate of the AlN samples with MCAS additive, all of which begin to shrink at $1300^{\circ} \mathrm{C}$, regardless of additive size. This is followed by accelerated shrinkage at $1300-1600^{\circ} \mathrm{C}$. The maximum shrinkage rates occur at $1535^{\circ} \mathrm{C}$ and $1575^{\circ} \mathrm{C}$ for the $\mathrm{AlN}$ samples with nanoand micro-additives, respectively. This is expected since a
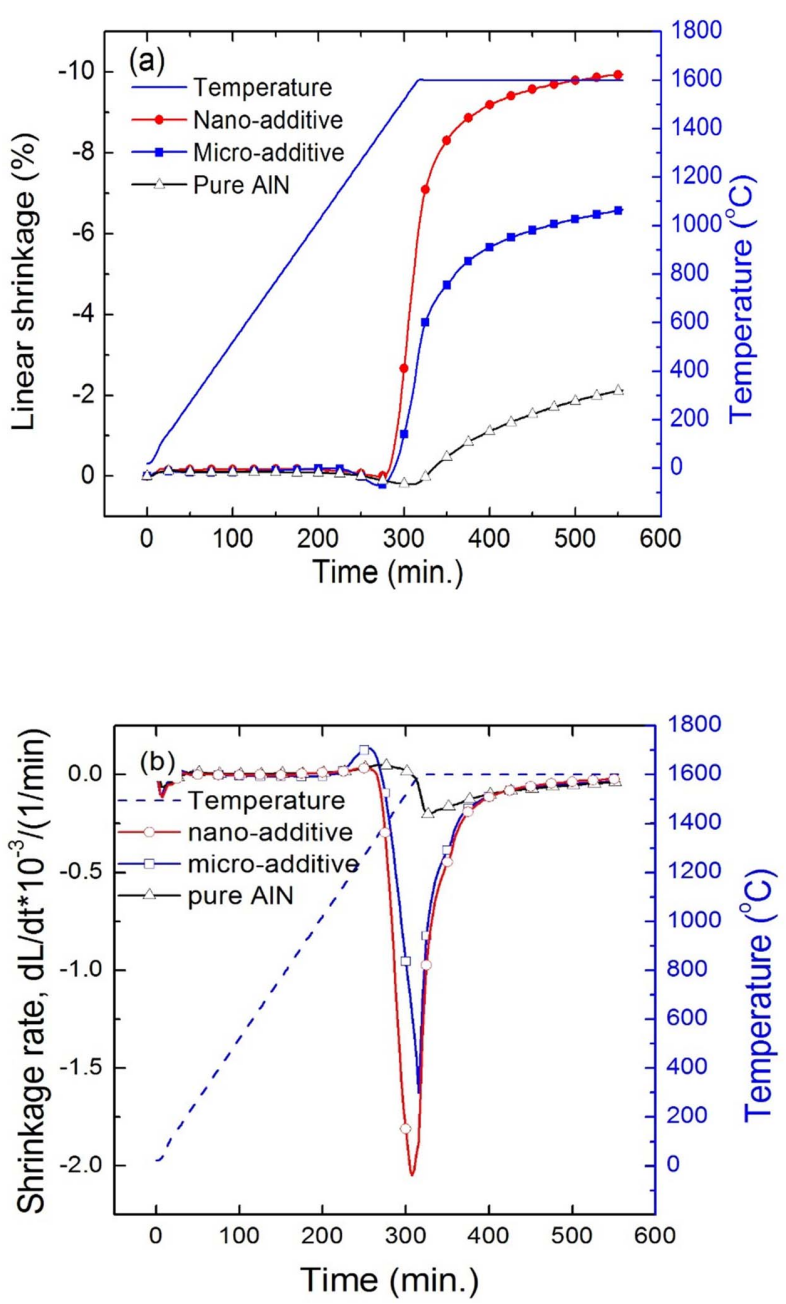

Fig. 3. Changes in (a) shrinkage and (b) shrinkage rate of the pure AlN compact and the AlN compact with 5 wt.\% of MCAS additive. finer additive can provide a higher driving force for densification.

\subsection{Sintered density}

Figure 4 shows the sintered densities of AlN made with 5 wt $\%$ of MCAS under $\mathrm{N}_{2}$ at different temperatures for $4 \mathrm{~h}$. Pure AlN sintered under the same conditions is included for comparison. The AlN with no additive exhibits a relatively low density even after sintering at $1700^{\circ} \mathrm{C}$. The addition of micro-MCAS results in a fast density increase starting at $1400^{\circ} \mathrm{C}$, and yields high sintered densities of $96.7,97.6 \%$, and $98.8 \%$ of the theoretical maximum at $1400^{\circ} \mathrm{C}, 1500^{\circ} \mathrm{C}$, and $1600^{\circ} \mathrm{C}$, respectively.

The addition of nano MCAS results in faster sintering, reaching $89.5 \%$ of the theoretical density at $1300^{\circ} \mathrm{C}$. This is expected since the finer additive can be distributed more uniformly and can spread AlN particles more quickly, providing enhanced sinterability. We assume that the decreased sintered density at $1700^{\circ} \mathrm{C}$ is due to the exaggerated grain growth of AlN, which normally traps pores.

\subsection{XRD Analysis}

Figure 5 shows XRD patterns of the AlN-5 wt\% MCAS samples sintered at $1600^{\circ} \mathrm{C}$ for $4 \mathrm{~h}$ in a $\mathrm{N}_{2}$ atmosphere. As shown in Fig. 5(a), most peaks belong to crystalline AlN, independent of additive size. No new secondary phase is identified, although a very weak peak appears at a $2 \theta$ of $34^{\circ}$. We also observe a diffuse halo-like peak at a $2 \theta$ of $20^{\circ}$, which normally indicates a noncrystalline phase, which may be melted MCAS.

Figure 5(b) shows the XRD pattern of Fig. 5(a) after removing the main AlN peaks so that the MCAS secondary phase can be observed more clearly. We thus determined that the minor crystalline peak belongs to a $\mathrm{Ca}-\mathrm{Al}$ compound $\left(\mathrm{Ca}_{3} \mathrm{Al}_{10} \mathrm{O}_{18}\right)$, which can form from the interaction and crystallization of $\mathrm{CaO}$ and $\mathrm{Al}_{2} \mathrm{O}_{3}$ from $\mathrm{MCAS}$ and $\mathrm{Al}_{2} \mathrm{O}_{3}$ on

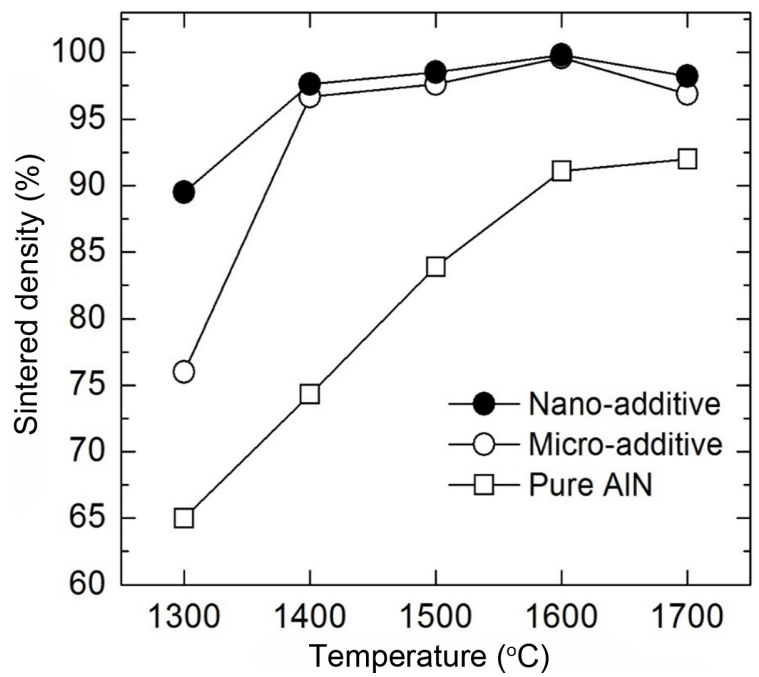

Fig. 4. Sintered density as a function of temperature of the pure AlN and the MCAS-doped AlN (5 wt.\%) specimens, sintered for $4 \mathrm{~h}$ in a $\mathrm{N}_{2}$ atmosphere. 

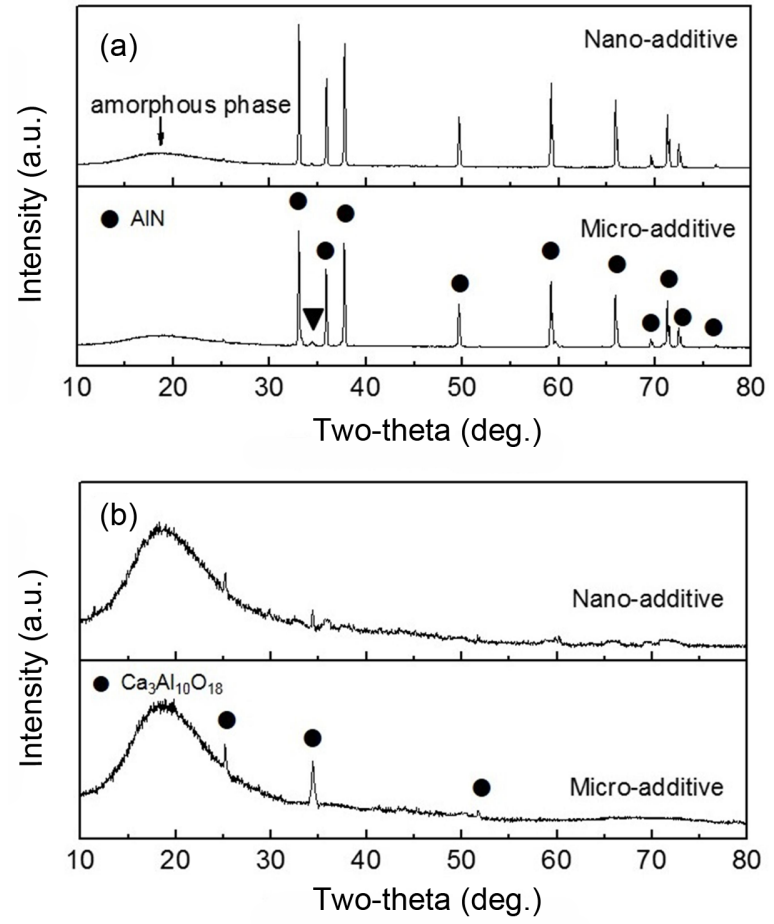

Fig. 5. XRD patterns of the MCAS-doped (5 wt.\%) AlN specimens sintered at $1600^{\circ} \mathrm{C}$ for $4 \mathrm{~h}$; (a) the original pattern and (b) the replotted pattern after deleting AlN peaks.

AlN surfaces. The $\mathrm{Ca}_{3} \mathrm{Al}_{10} \mathrm{O}_{18}$ phase forms in both MCASadded samples, although it is more obvious in the microadditive sample.

It has been well known that polycrystalline additives $\mathrm{Y}_{2} \mathrm{O}_{3}$ and $\mathrm{CaO}$ form liquid phases such as $\mathrm{Y}-\mathrm{Al}$ or $\mathrm{Ca}-\mathrm{Al}$ compounds during AlN sintering. This enhances densification by liquid phase sintering, and is followed by crystallization as a secondary phase. ${ }^{26)}$ In this study, however, the noncrystalline peak in the XRD patterns indicates that the sintering of AlN proceeds with the MCAS liquid via an enhanced mechanism even below $1600^{\circ} \mathrm{C}$. This mechanism features MCAS melts and consequent solution-reprecipitation of AlN particles. The MCAS additives provide the same sintering mechanism regardless of their particle sizes.

\subsection{Thermal conductivity}

Figure 6 shows the thermal conductivities of AlN samples with $5 \mathrm{wt} \%$ of MCAS that were sintered at $1600^{\circ} \mathrm{C}$ for $4 \mathrm{~h}$. The micro- and nano-additives result in thermal conductivities of 32.0 and $82.6 \mathrm{~W} / \mathrm{mK}$, respectively, demonstrating that the fine size of the nano-additive significantly enhances the thermal conductivity of AlN. Generally, increasing the amount of lattice oxygen in AlN decreases its thermal conductivity. ${ }^{14)} \mathrm{Y}_{2} \mathrm{O}_{3}$ is the most effective AlN additive for densification via liquid phase formation. It also decreases the amounts of oxygen on the AlN surface and in the AlN lattice, producing a thermal conductivity of about $170 \mathrm{~W} / \mathrm{mK}^{11,27)}$

Pressureless sintering or hot-pressing of polycrystalline

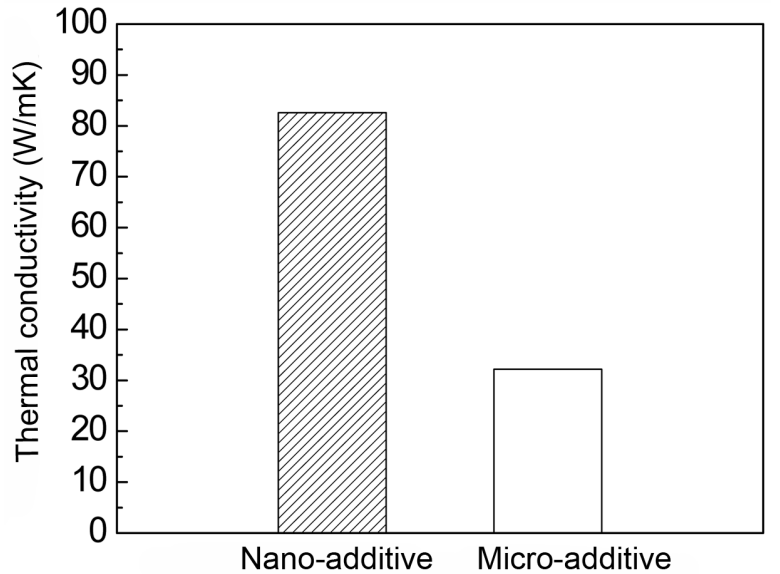

Fig. 6. Thermal conductivity of the MCAS-doped (5 wt.\%) AlN specimens sintered at $1600^{\circ} \mathrm{C}$ for $4 \mathrm{~h}$ in a $\mathrm{N}_{2}$ atmosphere at a heating rate of $5^{\circ} \mathrm{C} / \mathrm{min}$.

AlN with no additive yielded a thermal conductivity of about $80 \mathrm{~W} / \mathrm{mK}^{28)}$ This value is comparable to that of AlN with nano-MCAS, which is $82.6 \mathrm{~W} / \mathrm{mK}$. The results suggest that the nano-MCAS contributes to the low temperature sintering of AlN, but is unable to remove oxygen from the AlN lattice and thus produces a lower thermal conductivity than that of the AlN- $\mathrm{Y}_{2} \mathrm{O}_{3}$ system. The current most common packaging substrate, $\mathrm{Al}_{2} \mathrm{O}_{3}$, exhibits a thermal conductivity of only about $20 \mathrm{~W} / \mathrm{mK}$. Our thermal conductivity of $82.6 \mathrm{~W} / \mathrm{mK}$ is high enough to justify considering its replacement with AlN that has been sintered with nano-MCAS additive.

The low thermal conductivity of $32.0 \mathrm{~W} / \mathrm{mK}$ observed in the case of AlN sintered with micro-MCAS will be discussed during the subsequent microstructure analysis.

\subsection{Microstructure analysis}

Figure 7 is a back-scattered FE-SEM image of AlN with 5 $\mathrm{wt} \%$ of nano-MCAS after sintering at $1600^{\circ} \mathrm{C}$ for $4 \mathrm{~h}$ and fracturing to reveal its microstructure. We observe a fullydensified microstructure without any pores. In addition, we verify that AlN exhibits uniform, sharp-edged grains, and identify the MCAS secondary phase distributed along the grain boundaries.

Figure 8 is a back-scattered FE-SEM image of AlN with $5 \mathrm{wt} \%$ of the micro-MCAS additive after sintering and fracturing. This microstructure is different from the nano-additive case, as it exhibits non-uniformity and the presence of some pores. In particular, plate-shaped AlN grains form beside the spherical grains that are typical of liquid-phase sintered AlN bodies. These microstructural defects are attributed to unsatisfactory mixing between large microMCAS and AlN particles, which results in a considerable decrease in the thermal conductivity.

Baranda et $a ._{.}{ }^{29)}$ reported that the addition of $5 \mathrm{wt} \%$ of $\mathrm{SiO}_{2}$ to AlN with $3 \mathrm{wt} \%$ of $\mathrm{Y}_{2} \mathrm{O}_{3}$ decreases its thermal conductivity to $25 \mathrm{~W} / \mathrm{mK}$, and claimed that this is attributed to 


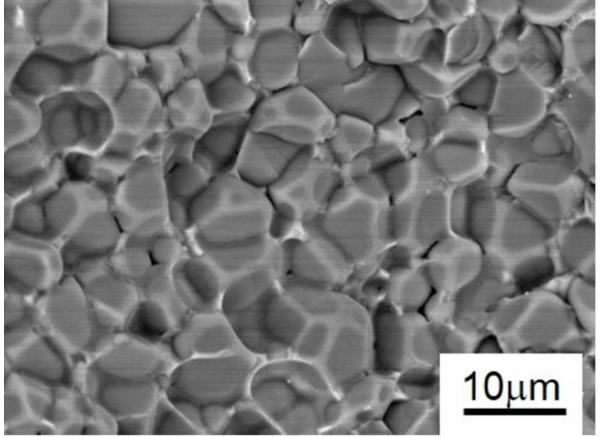

Fig. 7. FE-SEM image of the fracture surface of AlN specimen sintered with 5 wt.\% of nano-MCAS additive. Sintering was carried out at $1600^{\circ} \mathrm{C}$ for $4 \mathrm{~h}$.

microstructural defects created when the AlN lattice incorporates $\mathrm{SiO}_{2}$ and a polytypoid of SiALON forms. Thus, it is suspected that the plate-shaped grains formed in the micro additive case may be related to SiALON polytypoid ${ }^{29)}$ or a 27R polytype of $\mathrm{AlN},{ }^{30}$ ) since the $\mathrm{SiO}_{2}$ contained in the additive can react with AlN.

However, the XRD analysis in Fig. 5 shows no formation of a SiALON phase. Further microstructure analysis via methods such as TEM may be needed to explain the distribution of the MCAS noncrystalline secondary phase in the AlN grains, and to confirm whether the SiALON form is present.

\section{Conclusions}

In this study, we prepared two sintering additives for the densification of AlN, micro-sized MCAS synthesized via melting and nano-sized MCAS synthesized via the polymeric complex method. By measuring sintering shrinkage, we observed that $\mathrm{AlN}$ with $5 \mathrm{wt} \%$ of either additive densifies significantly in the $1300-1600^{\circ} \mathrm{C}$ temperature range. More shrinkage was observed when nano-sized MCAS was added. AlN with nano-sized MCAS exhibited its maximum shrinkage rate at $1535^{\circ} \mathrm{C}$, which is $40^{\circ} \mathrm{C}$ lower than that with micro-sized MCAS.

We also confirmed that the sintered densities at various sintering temperatures were higher when nano-MCAS was added. XRD analysis revealed that AlN with $5 \mathrm{wt} \%$ of either MCAS additive sintered at $1600^{\circ} \mathrm{C}$ by forming most of its secondary phase as a noncrystalline phase. We thus determined that the densification of AlN proceeded via a liquidphase mechanism using melted MCAS.

AlN bodies sintered at $1600^{\circ} \mathrm{C}$ exhibited thermal conductivities of 82.6 and $32 \mathrm{~W} / \mathrm{mK}$ with $5 \mathrm{wt} \%$ additions of nano- and micro-MCAS, respectively. From these results, we verified that the MCAS particle size is important to the densification and thermal conductivity of AlN. We also concluded that preparing the additive at the nanoscale is an effective method of sintering and enhancing the sintered properties.

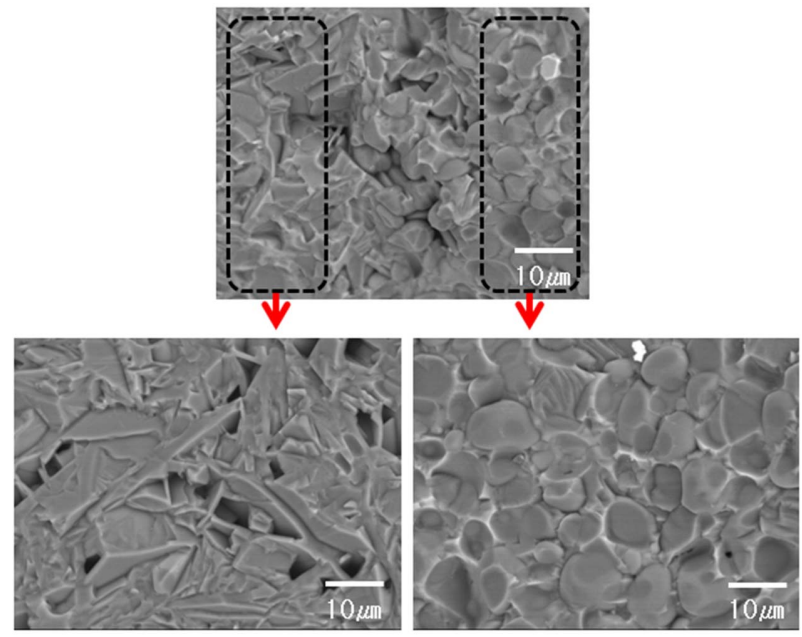

Fig. 8. FE-SEM images for the sintered AlN specimen with 5 wt.\% of micro-MCAS additive. Sintering was carried out at $1600^{\circ} \mathrm{C}$ for $4 \mathrm{~h}$.

\section{Acknowledgments}

This research was supported by the Korea Institute for the Advancement of Technology.

\section{REFERENCES}

1. Y. Baik and R. A. L. Drew, "Aluminum Nitride: Processing and Applications," Key Eng. Mater., 122-124 553 (1996).

2. R. E. Simons, "Thermal Management of Electronic Packages," Solid State Technol., 26 [10] 131-37 (1983).

3. C. Zweben, "Adv. Comp. Mater. for Thermal Management in Electronic Packaging," JOM, 50 [6] 47-51 (1998).

4. Y. Kurokawa, Z. Utsumi, H. Takamizawa, T. Kamata, and S. Noguchi, "AlN Substrates with High Thermal Conductivity," IEEE Trans. Comp., Hybrids, Manuf. Technol., 8 [2] 247-52 (1985).

5. T. B. Jackson, A. V. Virkar, K. L. More, R. B. Dinwiddie, and R. A. Cutler, "High-Thermal-Conductivity Aluminum Nitride Ceramics: the Effect of Thermodynamic, Kinetic, and Microstructural Factors," J. Am. Ceram. Soc., 80 [6] 1421-35 (1997).

6. A. V. Virkar, T. B. Jackson, and R. A. Cutler, "Thermodynamic and Kinetic Effect of Oxygen Removal on the Thermal Conductivity of Aluminum Nitride," J. Am. Ceram. Soc., 72 [11] 2031-42 (1989).

7. G. A. Slack, "Nonmetallic Crystals with High Thermal Conductivity," J. Phys. Chem. Solids, 34 [2] 321-35 (1973).

8. L. M. Sheppard, "Aluminum Nitride: A Versatile but Challenging Material," Am. Ceram. Soc. Bull., 69 [11] 1801-3 (1990)

9. K. Komeya, H. Inoue, and A. Tsuge, "Role of $\mathrm{Y}_{2} \mathrm{O}_{3}$ and $\mathrm{SiO}_{2}$ Additions in Sintering of AlN," J. Am. Ceram. Soc., 57 [9] 411 (1974).

10. K. Komeya, A. Tsuge, H. Inoue, and H. Ohta, "Effect of $\mathrm{CaCO}_{3}$ Addition on the Sintering of AlN," J. Mater. Sci. Lett., 1 [8] 325-26 (1982).

11. N. Kuramoto, H. Taniguchi, and I. Aso, "Development of 
Translucent Aluminum Nitride Ceramics," Am. Ceram. Soc. Bull., 68 [4] 883-87 (1989).

12. A. L. Molisani, H. N. Yoshimura, H. Goldenstein, and K. Watari, "Effects of $\mathrm{CaCO}_{3}$ Content on the Densification of Aluminum Nitride," J. Eur. Ceram. Soc., 26 [15] 3431-40 (2006).

13. T. B. Troczynski and P. S. Nicholson, "Effect of Additives on the Pressureless Sintering of Aluminum Nitride between $1500^{\circ} \mathrm{C}$ and $1800^{\circ} \mathrm{C}$," J. Am. Ceram. Soc., 72 [8] 1488-91 (1989).

14. E. Treicher, T. Chartier, P. Bosch, M. F. Denanot, and J. Rabier, "Densification and Thermal Conductivity of LowSintering-Temperature AlN Materials," J. Eur. Ceram. Soc., 6 [1] 23-9 (1990).

15. J. Jarrige, K. Bouzouita, C. Doradoux, and M. Billy, "A New Method for Fabrication of Dense Aluminium Nitride Bodies at a Temperature as Low as $1600^{\circ} \mathrm{C}$," J. Eur. Ceram. Soc., 12 [4] 279-85 (1993).

16. K. Watari, H. J. Hwang, M. Toriyama, and S. Kanzaki, "Effective Sintering Aids for Low-Temperature Sintering of AlN Ceramics," J. Mater. Res., 14 [4] 1409-17 (1999).

17. Y. Liu, H. Zhou, L. Qiao, and Y. Wu, "Low-Temperature Sintering of Aluminum Nitride with $\mathrm{YF}_{3}-\mathrm{CaF}_{2}$ Binary additive," J. Mater. Sci. Lett., 18 [9] 703-4 (1999).

18. L. Qiao, H. Zhou, H. Xue, and S. Wang, "Effect of $\mathrm{Y}_{2} \mathrm{O}_{3}$ on Low Temperature Sintering and Thermal Conductivity of AlN Ceramics," J. Eur. Ceram. Soc., 23 [1] 61-7 (2003).

19. C. M. Cheng, C. F. Yang, S. H. Lo, and T. S. Tseng, "Sintering $\mathrm{BaTi}_{4} \mathrm{O}_{9} / \mathrm{Ba}_{2} \mathrm{Ti}_{9} \mathrm{O}_{20}$-Based Ceramics by Glass Addition," J. Eur. Ceram. Soc., 20 [8] 1061-67 (2000).

20. Q. Zhang, G. Jiang, H. Zhuang, W. Li, X. Fu, and D. Yan, "Effects of Gravity on the Microstructure of AlN/Glass Composites," Mater. Sci. Eng. A, 352 [1] 217-20 (2003).

21. C. F. Yang, C. M. Cheng, H. H. Chung, and C. C. Chan, "Sintering AlN Ceramics Below $1500^{\circ} \mathrm{C}$ with $\mathrm{MgO}-\mathrm{CaO}-$ $\mathrm{Al}_{2} \mathrm{O}_{3}-\mathrm{SiO}_{2}$ Glass Addition," Key Eng. Mater., 336-338 186871 (2007).
22. H. J. Lee, S. W. Kim, and S. S. Ryu, "Sintering Behavior of Aluminum Nitride Ceramics with $\mathrm{MgO}-\mathrm{CaO}-\mathrm{Al}_{2} \mathrm{O}_{3}-\mathrm{SiO}_{2}$ Glass Additive," Int. J. Refract. Met. Hard Mater., 53 46-50 (2015).

23. H. M. Lee, K. Bharathi, and D. K. Kim, "Processing and Characterization of Aluminum Nitride Ceramics for High Thermal Conductivity," Adv. Funct. Mater., 16 [6] 655-69 (2014).

24. J. Y. Qiu, Y. Hotta, and K. Watari, "Enhancement of Densification and Thermal Conductivity in AlN Ceramics by Addition of Nano-Sized Particles," J. Am. Ceram. Soc., 89 [1] 377-80 (2006).

25. H. J. Lee, W. S. Cho, H. J. Kim, W. Pan, M. Shahid, and S. $\mathrm{S}$. Ryu, "Synthesis of $\mathrm{MgO}-\mathrm{CaO}-\mathrm{Al}_{2} \mathrm{O}_{3}-\mathrm{SiO}_{2}$ Nano Powder by Polymeric Complex Method as a Novel Sintering Additive of AlN Ceramics," Electron. Mater. Lett., 12 [6] 732-37 (2016).

26. A. L. Molisani, H. N. Yoshimura, and H. Goldenstein, "Sintering Mechanisms in Aluminum Nitride with Y or CaContaining Additive," J. Mater. Sci.: Mater. Electron., 20 [1] 1-8 (2009).

27. A. V. Virkar, T. B. Jackson, and R. A. Cutler, "Thermodynamic and Kinetic Effects of Oxygen Removal on the Thermal Conductivity of Aluminum Nitride," J. Am. Ceram. Soc., 72 [11] 2031-42 (1989).

28. Y. Kurokawa, K. Utsumi, and H. Takamizawa, "Development and Microstructural Characterization of High-Thermal Conductivity Aluminum Nitride Ceramics," J. Am. Ceram. Soc., 71 [7] 588-94 (1988).

29. P. S. De Baranda, A. K. Knudsen, and E. Ruh, "Effect of $\mathrm{SiO}_{2}$ on the Thermal Conductivity of Aluminum Nitride," $J$. Am. Ceram. Soc., 76 [7] 1761-71 (1993).

30. T. Yagi, K. Shinozaki, N. Ishizawa, N. Mizutani, and M. Kato, "Effect of Silicon Dioxide on the Thermal Diffusivity of Aluminum Nitride," J. Am. Ceram. Soc., 71 [7] C334-38 (1988). 